Full length article

\title{
Meeting expectations: The effects of expectations on self-esteem following the construction of a dating profile
}

\author{
Dian A. de Vries \\ Department of Youth and Family, Utrecht University, Heidelberglaan 1, 3584 CS Utrecht, The Netherlands
}

\section{A R T I C L E I N F O}

\section{Article history:}

Received 10 November 2015

Received in revised form

18 March 2016

Accepted 19 March 2016

\section{Keywords:}

Online self-presentation

Impression management

Self-esteem

Online dating

Computer-mediated communication

Mode-switching

\begin{abstract}
A B S T R A C T
Online daters may be aware that online chat can extend their opportunities for making a desirable impression on potential dates in comparison to meeting a potential partner face-to-face. This anticipation of a subsequent interaction may already impact the impression individuals expect to make through an online profile initially, which in turn can impact self-esteem. We tested these hypotheses in an experiment. Ninety-two heterosexual women constructed a dating profile while anticipating that they would meet a date either face-to-face or through text-based chat. Participants who anticipated computer-mediated (as opposed to face-to-face) interaction expected that their profile would make a more desirable impression on a potential date. Furthermore, the anticipation of computer-mediated interaction increased romantic self-esteem through the increased expectation of making a desirable impression.
\end{abstract}

() 2016 Elsevier Ltd. All rights reserved.
Research showing a link between computer-mediated communication (CMC) and self-esteem has started to accumulate (e.g., Gross, 2009; Shaw \& Gant, 2002; Valkenburg, Peter, \& Schouten, 2006; Yang \& Brown, 2016). For example, survey research shows that most adolescents' social network site profiles evoke positive responses from viewers, which, in turn, are positively related to self-esteem (Valkenburg et al., 2006). The current body of research (e.g., Gross, 2009; Shaw \& Gant, 2002; Valkenburg et al., 2006; Yang \& Brown, 2016) tells us much about how self-esteem is affected by online interaction when interaction partners have responded to each other. However, we currently know little about what determines self-esteem when no responses from interaction partners have been received yet, as is the case, for example, when individuals are still waiting for responses to their dating profile. When online daters have not yet received any responses from potential dates and no interaction has taken place yet, expectations about these responses and interactions may influence their selfesteem. The current experiment focuses on two types of expectations related to $\mathrm{CMC}$ that may impact self-esteem.

The first type of expectation involves the kind of reactions the dater anticipates. Research has shown that feedback in response to online profiles is related to self-esteem (Valkenburg et al., 2006).

E-mail address: d.a.devries@uu.nl.
However, before any feedback has been received, the expected feedback of potential viewers may already impact self-esteem. Although the idea that individuals' views of themselves are influenced by how they think other people will respond to them in the future is not new (e.g., Leary \& Kowalski, 1990; Schlenker \& Leary, 1982), it has not yet been applied extensively to asynchronous CMC. We thus do not know whether individuals' expectations about others' reactions to their online profiles impact their self-esteem. The current study therefore explores the relationship between online daters' expectations of how their profile will be perceived by potential dates and their own self-esteem.

A second type of expectations that may influence self-esteem involves the mode (i.e., face-to-face $[\mathrm{FtF}]$ or $\mathrm{CMC}$ ) in which interactions will take place. In online dating, some couples choose to meet FtF (almost) immediately whereas others spend quite some time chatting to each other through CMC or even choose to never meet in person (Blackhart, Fitzpatrick, \& Williamson, 2014; Finkel, Eastwick, Karney, Reis, \& Sprecher, 2012; Lawson \& Leck, 2006). Previous research indicates that both the anticipated and actual mode of relational communication can impact the impressions interaction partners form of each other (Gibbs, Ellison, \& Heino, 2006; McLaughlin, Vitak, \& Crouse, 2011; Ramirez, Sumner, Fleuriet, \& Cole, 2015; Sprecher, 2014). However, most studies surveyed participants after they had exchanged messages with potential partners and/or had gone on dates (Gibbs et al., 
2006; Ramirez et al., 2015). We thus do not know if anticipations of the mode of the subsequent interaction impact the impressions online daters expect to make through their online profile already before this profile is viewed by potential dates. Furthermore, we do not know if, potentially as a result of these effects on the impressions online daters expect to make, expectations about subsequent mode of interaction affect their self-esteem. The current study aims to determine which strategy is more beneficial to the self-esteem of online daters: planning to chat with a potential date online first or intending to meet FtF straight away. Furthermore, we test if these potential differences can be explained by differences in the impressions online daters expect to make on potential dates through their profile.

\section{The two-component model of impression management}

An impression management perspective is a useful approach to predict and explain online daters' expectations about the impressions they will make and their self-esteem. Impression management, or self-presentation (the two terms are generally used interchangeably), is the process through which individuals try to control the impression that others have of them (Leary \& Kowalski, 1990). Impression management plays a central role in most interpersonal interactions as the impressions people make on others determine how they will be seen and treated by these others (Baumeister, 1982). In online dating, interactions with potential partners are central and the impressions made on these potential partners are crucial for determining one's success in starting a romantic relationship, the general goal of online dating (Ellison, Heino, \& Gibbs, 2006). It is therefore not surprising that academics who study online dating often take an impression management approach (e.g., Ellison et al., 2006; Gibbs et al., 2006; Hall, Park, Song, \& Cody, 2010).

Scholars have extensively studied self-presentation in its offline form and developed models explaining and predicting selfpresentation behavior and effects (e.g., Baumeister, 1982; Leary \& Kowalski, 1990; Schlenker \& Leary, 1982). In particular, the twocomponent model of impression management (Leary \& Kowalski, 1990) offers nuanced theoretical propositions describing why and when people will engage in impression management and factors that promote, limit, and/or shape individuals' self-presentation strategies. This model has also been successfully applied to impression management in online dating (Toma \& Hancock, 2010). The two-component model also describes how and why impression management can impact self-esteem (Leary \& Kowalski, 1990). We therefore considered the two-component model to be a useful framework for studying factors that impact individuals' self-esteem during online dating.

The two-component model describes two distinct components of impression management: impression motivation and impression construction (Leary \& Kowalski, 1990). Impression motivation is the degree to which people wish to control the impression others have of them (Leary \& Kowalski, 1990). Impression construction comes into play once individuals are motivated to control the impression they make on others (Leary \& Kowalski, 1990). During impression construction individuals decide which self-presentational strategies to employ in order to affect others' impressions of them (Leary \& Kowalski, 1990). When online daters construct a dating profile, they are likely motivated to control the impressions they will make through this profile, as it will affect their chances to attract a desirable romantic partner (Toma \& Hancock, 2010). We therefore assumed that singles engage in impression construction when they construct an online dating profile (Toma \& Hancock, 2010).

\section{Impression management and self-esteem}

According to the two-component model, impression management is not only important for relationships and social interaction but also crucial for individuals' self-esteem (Leary \& Kowalski, 1990). Leary and Kowalski (1990) describe two ways in which impression management impacts self-esteem. First, when one is effective at making a positive impression on others, this can evoke praise and compliments and prevent criticism and rejection from others (Leary \& Kowalski, 1990). Receiving positive feedback can raise individuals' self-esteem whereas receiving negative feedback can be detrimental to self-esteem (Leary \& Kowalski, 1990). Second, self-esteem is affected by how people think they performed in their self-presentation (Leary \& Kowalski, 1990). When people think that they have made a positive impression on others this raises their self-esteem (Leary \& Kowalski, 1990).

Presenting the self to one or more others can thus affect selfesteem even in the absence of actual feedback, merely through imagined reactions from others. In the context of self-presentation through an online profile not only the reactions of others can be imagined but these others themselves can also be imagined (boyd, 2010; Litt, 2012). In computer-mediated communication sender and receiver are separated in time and space (Walther, 1996). Individuals therefore generally do not know exactly who will see their profile. This is especially true in online dating where a profile is constructed before any contacts or matches have been identified. However, when people construct a profile they do have an audience in mind that they expect or would like to reach (boyd, 2010; Litt, 2012). In the case of online dating this imagined audience most likely consists of the romantic partners that the individual aims to attract. Based on the two-component model (Leary \& Kowalski, 1990) it is conceivable that online daters imagine how their audience, potential romantic partners, will respond to their profile. Furthermore, the two-component model (Leary \& Kowalski, 1990) predicts that these imagined reactions will influence the self-esteem of the individual constructing the profile. Individuals may thus adapt their selfesteem in the direction of the impression they expect to make on others through their profile: the more positive the impression is that they expect to make, the more positive their self-esteem will be.

Self-esteem is a broad term and general self-esteem is made up of an individual's self-esteem in different subdomains (Swann, Chang-Schneider, \& Larsen McClarty, 2007). When investigating determinants of self-esteem it is most fruitful to focus on selfesteem specifically in the domain that is most relevant to the context and most likely to be influenced by the factors under study (Swann et al., 2007). In the current context of online dating, the degree to which the individual sees the self as a desirable romantic partner, that is, romantic self-esteem (Harter, 1988), is of particular relevance. Based on the preceding discussion and the twocomponent model, romantic self-esteem of online daters is expected to depend at least partly on the degree to which they believe that potential dates will see them as a desirable date or romantic partner. In the current study, we test if this prediction holds when there is an imagined online audience who individuals have not yet interacted with. We hypothesize:

H1. Romantic self-esteem is higher among online daters who expect that their profile will make a desirable impression on potential dates.

\section{Impression management in computer-mediated communication}

According to the hyperpersonal model of CMC (Walther, 1996, 2007), interaction partners who get to know each other online 
will form more positive impressions of each other than those who get to know each other FtF. A number of sociotechnical affordances of CMC facilitate the exchange of these desirable impressions (Walther, 1996, 2007). First, online self-presentations are editable (Walther, 2007). One can easily adjust a self-presentation message by re-writing it until it appears how one most wants it. Second, the asynchronous nature of CMC affords users more time to think about, and deliberately create, a desired self-presentation than more spontaneous FtF self-presentation (Walther, 2007). Third, CMC offers reduced cues relative to FtF communication (Walther, 2007). As a result, individuals can maximize the salience of desired qualities and minimize the salience of undesired qualities more readily than in offline encounters. Fourth, editability and asynchronicity in CMC together facilitate the allocation of greater cognitive resources to impression construction. In FtF selfpresentation, a presenter needs to divide attention between controlling non-verbal and verbal self-presentation behavior and monitoring the responses of others (Walther, 2007). In contrast, CMC separates sender from receiver, allowing its user to focus entirely on message construction (Walther, 2007).

The affordances of CMC may thus facilitate more positive impression construction (Walther, 1996, 2007) by enhancing control over the messages one constructs about the self (Schouten, Valkenburg, \& Peter, 2007). In addition, the affordances of CMC may facilitate positive impression formation (Walther, 1996). Interaction partners fill in the blanks left in CMC in a way that fits with their initial impression of their partner (Walther \& Tong, 2014). Because this initial impression is positively biased in CMC relative to $\mathrm{FtF}$, these blanks tend to be filled in a positive manner during impression formation (Walther \& Tong, 2014). As a result, interaction partners form more desirable views of each other during CMC than during FtF interaction (Walther, 1996).

Individuals generally seem to be aware that CMC facilitates constructing and forming desirable impressions and make use of the affordances of CMC when they construct an online profile (Ellison, Hancock, \& Toma, 2012; Toma \& Carlson, 2015). People present themselves desirably when they construct a dating profile by editing and carefully selecting information and pictures to look more appealing to potential dates (Ellison et al., 2012; Toma \& Hancock, 2010). Furthermore, individuals report that they think their own online (Facebook) profile presents them in a positive manner (Toma \& Carlson, 2015). The imminence of a FtF encounter, however, may limit the degree to which individuals feel able to make use of the hyperpersonal affordances of CMC to make desirable impressions on potential dates (Gibbs et al., 2006; McLaughlin et al., 2011).

\section{Impression management and expectations about future interaction}

The hyperpersonal model of computer-mediated communication and two-component model together predict that singles will construct desirable impressions when sending computer-mediated messages to potential partners (Leary \& Kowalski, 1990; Walther, 1996, 2007). The affordances of CMC allow online daters to construct and form desirable impressions (Walther, 2007) both in the exchange of online dating profiles as well as in potential subsequent computer-mediated chat conversations. However, for most online daters, the goal of online dating is to eventually get to know a potential partner FtF and to establish an offline relationship (Finkel et al., 2012). FtF interactions afford less positive impression construction and formation than CMC as they lack the affordances for impression management that CMC offers (Walther, 1996, 2007).

When online daters construct their dating profile, they may already keep in mind potential future interactions with matches who will have first seen this profile (Gibbs et al., 2006). According to the two-component model, people will only attempt to make impressions that they believe they can live up to in successive encounters with the same individuals (Leary \& Kowalski, 1990). Making an impression that cannot be sustained is not desirable because deviations between two self-presentational acts can be perceived as dishonest and inconsistent (DeAndrea \& Walther, 2011), and trustworthiness is an important predictor of interpersonal attraction (Jin \& Martin, 2015). Expectations about future meetings thus affect initial impression construction behaviors (Leary \& Kowalski, 1990). As successful online dating will consist of consecutive interactions, online daters will only communicate impressions in an initial message that they believe they will be able to sustain during subsequent interaction.

The degree to which online daters believe they can live up to the impression conveyed through an online profile in a subsequent interaction may be affected by the mode in which this subsequent interaction will take place. When this subsequent interaction, like the profile, is computer-mediated, daters can keep making use of the affordances of $\mathrm{CMC}$ and live up to a more desirable impression than when this subsequent interaction is FtF. Daters who expect to engage in CMC should thus feel more able to sustain a desirable impression that they can convey initially through their dating profile than daters who expect FtF interaction to follow the exchange of profiles.

Individuals will already take into account the impression they expect to make in the subsequent interaction when constructing an initial impression (Leary \& Kowalski, 1990). Therefore, online daters likely make more use of the affordances of CMC to construct a desirable impression in an online profile when they expect that they will also be able to make use of these affordances in a subsequent interaction. In other words, when online daters expect a subsequent interaction to be computer-mediated, they will construct a more desirable impression through their online profile than when they expect a subsequent interaction to be FtF. In line with this notion, it has been shown that individuals presented themselves more attractively online if they were led to anticipate CMC interaction in the future than if they were led to expect face-to-face interaction (McLaughlin et al., 2011). Furthermore, online daters who aimed to meet a romantic partner FtF reported that their online profile was more honest than singles who did not intend to move their relationship offline (Gibbs et al., 2006). On the basis of the hyperpersonal model, the twocomponent model, and previous empirical research it can thus be predicted that:

H2. Singles who anticipate that $C M C$ interaction will follow the exchange of online profiles expect that their dating profile will make a more desirable impression on potential dates than singles who anticipate that FtF interaction will follow the exchange of online profiles.

Because we predict that the degree to which online daters expect to make a desirable impression on potential dates is positively related to their romantic self-esteem (H1), we also hypothesized:

H3. a) Singles who anticipate that CMC interaction will follow the exchange of online profiles report higher romantic self-esteem than singles who anticipate that FtF interaction will follow the exchange of online profiles b) through an increased expectation that their dating profile will make a desirable impression on potential dates.

H3a and H3b jointly thus predict that the effect of anticipated mode of interaction on romantic self-esteem will be mediated by the desirability of the expected impression made through the online profile. This hypothesized mediation is visualized in Fig. 1. 


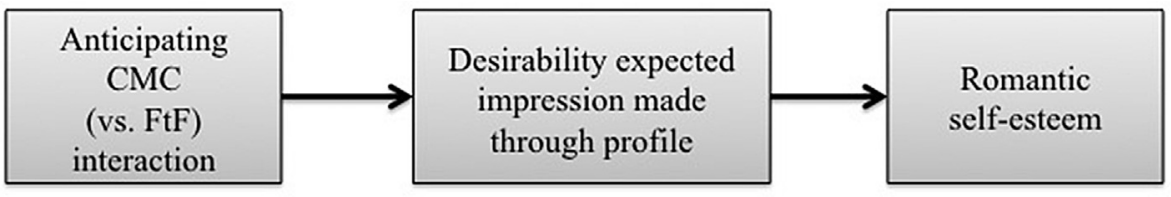

Fig. 1. Hypothesized mediation model.

\section{Method}

Our hypotheses were tested in a randomized experiment. Single heterosexual female participants constructed an online dating profile and completed a survey. Participants were told that they would converse, in the future, with a prospective male date either via $\mathrm{CMC}$ or $\mathrm{FtF}$.

\subsection{Participants}

One hundred single, heterosexual women were recruited and included in the experiment. Patterns similar to those described in the hypotheses above can be expected among heterosexual men and homosexual and bisexual men and women. However, due to differences in how women and men present themselves on dating profiles and what they look for in a partner (Hall et al., 2010), a heterogeneous sample in terms of gender and sexual orientation would yield much error variance and reduce statistical power. We therefore chose a more homogeneous sample of heterosexual women.

Five participants' data were excluded from the final sample because they were suspicious of the goal of the study or did not meet screening criteria. Three other participants were excluded because they were unable or unwilling to meet a potential date. The final sample thus consisted of $N=92$ female participants, which offers sufficient power $(0.80)$ to detect a medium effect size at a significance level of 0.05 (Cohen, 1992). Participants were compensated with 5 euro or course credit.

Participants' ages ranged from 18 to $41(M=21.8, S D=3.4)$. In terms of ethnicity/race, a majority (81.5\%) labelled themselves as "white." Most participants (78.3\%) reported no experience with online dating, 9.8\% had made a profile but never had any interaction with people through a dating site, $3.3 \%$ had interacted online with a prospective date but had not been on a FtF date, and $8.7 \%$ had been on a date with someone who they had met through online dating.

\subsection{Procedure}

Participants reported to a research lab individually. The researcher first checked if the participant met the screening criteria (single, heterosexual, and female) and then provided the participant with written information about the experiment. After obtaining their informed consent, a researcher randomly assigned participants to one of the experimental conditions. The experimenter then verbally provided the participants with the following

\footnotetext{
1 The experiment was originally based on a 2 (anticipated mode of subsequent interaction: FtF vs. CMC) x 2 (forewarning of measuring height and weight: yes vs. no) between-subjects design. The second factor was manipulated for purposes outside the scope of the current study: Participants were either told or not told that their weight and height would be measured after they finished constructing their profiles. The forewarning condition was included as a covariate in the analyses reported below, but did not have any effects on outcomes relevant to this investigation (expected impression made through profile and romantic self-esteem). The factor also did not moderate the relationships between the different variables.
}

information:

"We are interested in the process of online dating. In the current study we ask you to make a dating profile. This profile contains a description of the man who you may like to meet and some information about you, such as your age, study program, height, weight, hobbies, interests, and personality. ${ }^{2}$ In three to six weeks, our computer program will make a match between our male and female participants. If a match has been made, which will usually be the case, we will exchange the dating profiles between you and your match and will organize a (face-to-face or online chat session) so that you can get to know each other (face-to-face or via chat)."

Participants used a laptop computer to complete a dating profile consisting of a range of open- and closed-ended questions. These questions resembled the profile components of a popular online dating site in the country where this research took place. After completing the profile, participants were shown a screen with the following information: "Your profile is complete! We will now ask you a number of questions that are completely anonymous and will therefore not appear on your profile!"

Participants then responded to questions about the profile that they had constructed in order to measure their expectation about the impression their profile would make and completed a measure of romantic self-esteem, embedded in a battery of other questionnaires, and summoned the experimenter when they had finished. The experimenter subsequently asked participants to fill out a final form containing a manipulation check, a probe for suspicion, and demographic questions. The researcher debriefed participants collectively, through e-mail, when data collection was complete. The research ethics committee of the university where the study was conducted approved all procedures.

\subsection{Measures}

\subsubsection{Manipulation check}

A manipulation check verified whether participants anticipated a CMC or FtF meeting with a prospective date congruent with their assigned condition. Participants selected among three options to complete the following sentence: "If the computer finds a match between me and a man (a) a face-to-face meeting will take place, (b) a computer-mediated chat session will take place, or (c) I wasn't told."

\subsubsection{Expected impression made through profile}

This measure was constructed specifically for the purpose of the current study as, to our knowledge, no adequate measure existed. Participants rated how they thought a potential match would see them when viewing their profile with respect to 13 positive attributes ("When a potential match sees my profile, I think he will see me as ..."). These attributes included four items related to physical qualities (e.g., sexy, pretty, attractive) and nine items reflecting personal qualities (e.g., intelligent, caring, adventurous). Responses

\footnotetext{
2 In the forewarning of measuring height and weight condition a scale and measuring tape were present and participants were also told "at the end of the session, your height and weight will be verified."
} 
could vary between 1 (not at all) and 10 (very much). Higher mean scores on these positive characteristics, as a composite, reflected the expectation of making a more desirable impression through the profile, Cronbach's $\alpha=0.90, M=6.11, S D=1.10$.

\subsubsection{Romantic self-esteem}

To measure romantic self-esteem, we asked participants to complete a shortened, four-item version of the romantic appeal subscale of the Harter (1988) self-perception profile, as translated and adapted by Valkenburg et al. (2006). An example of an item is "Others fall in love with me easily." Responses could range from 1 (disagree entirely) to 5 (agree entirely). Scores on the four items were computed into a mean score. Higher scores reflect greater romantic self-esteem, Cronbach's $\alpha=0.71, M=3.08, S D=0.66$.

\section{Results}

Before testing the hypotheses, we examined whether there were any differences between the four conditions of the original experimental design (see Footnote 1) regarding participants' background characteristics. Chi-square analyses showed that the conditions did not differ significantly with regard to race/ethnicity, $\chi^{2}(6, N=92)=6.054, p=.417$, or online dating experience, $\chi^{2}(9$, $N=92)=6.308, p=.709$, of the participants. All participants correctly indicated the mode of subsequent interaction they expected on the manipulation check. The manipulation was thus deemed successful.

We calculated the zero-order correlation among desirability of the expected impression made through the profile and romantic self-esteem. This positive and statistically significant correlation, $r=0.504, p<0.001$, provides initial support for hypothesis 1 . Due to the continuous nature of the outcome variables and the mix of continuous and categorical predictor, mediating, and control variables, we formally tested the hypothesized model (Fig. 1) using a series of regression analyses. ${ }^{3}$

We first tested the effect of condition, anticipated mode of subsequent interaction, on the outcome variable, romantic selfesteem. Regression analysis with the CMC condition coded " 1 " and the FtF condition coded " 0 " showed that participants who anticipated CMC indeed reported higher romantic self-esteem $(M=3.23, S D=0.65)$ than participants who anticipated FtF interaction $(M=2.90, S D=0.62), \beta=0.255, B=0.334, S E=0.135$, $p=0.015$. Hypothesis 3a was thus supported.

We then tested the effect of the condition, anticipated mode of subsequent interaction, on the mediating variable, expected impression made through profile. Regression analysis with the CMC condition coded " 1 " and the FtF condition coded " 0 " showed that participants who anticipated CMC expected to make more desirable impressions through their profile $(M=6.53, S D=1.02)$ than participants anticipating $\mathrm{FtF}$ interaction $(M=5.62, S D=0.98)$, $\beta=0.415, B=0.907, S E=0.212, p<0.001$. Hypothesis 2 was therefore supported.

We then regressed the outcome variable, romantic self-esteem, on both the manipulation (anticipated mode of subsequent interaction) and the mediator (expected impression made through profile). In line with hypothesis 1 , expected impression made through profile was positively related to romantic self-esteem, $\beta=0.482, B=0.289, S E=0.061, p<0.001$. The predictor anticipated mode of subsequent interaction was no longer significant, $\beta=0.055, B=0.072, S E=0.133, p=0.592$, which is a first indication that the expectation of the profile making a desirable impression

\footnotetext{
${ }^{3}$ Forewarning of measuring height and weight condition were included as a control variable in each analysis.
}

fully mediated the effect of anticipated mode of subsequent interaction on romantic self-esteem, as predicted in Hypothesis 3b.

We also tested the indirect effect (H3b) of anticipated mode of subsequent interaction on romantic self-esteem through expected impression made through profile using SPSS macro PROCESS (Hayes, 2012). The test of indirect effects employed PROCESS for SPSS model 4 with 1000 bootstrapped samples. The indirect effect of anticipating CMC (vs. FtF interaction), through expected impression made through profile, was positive and significant, $B=0.262, S E=0.078$ (Bt bca 95\% CI: 0.134/0.438). In line with our hypotheses, the results thus show that anticipating CMC increased romantic self-esteem and this effect was fully mediated by the expectation to make a more desirable impression through the profile.

\section{Discussion}

In the current study, (female heterosexual) online daters who anticipated that CMC would follow the exchange of online profiles reported higher romantic self-esteem after the construction of a dating profile than those anticipating FtF interaction. This effect was mediated by an increased expectation of making a desirable impression through the dating profile. These results are in line with our hypotheses. The findings offer a number of theoretical and practical implications and can guide further research.

\subsection{Theoretical and practical implications}

The current study has some practical implications for online daters. In the period between the construction of the dating profile and the reception of responses, online daters who expected that they would chat to a potential date online after the exchange of profiles reported higher romantic self-esteem than online daters who anticipated FtF interaction straight away. Online daters who want to protect or enhance their self-esteem during the period of waiting for responses to their profile should thus plan to engage in CMC first rather than intending to meet FtF straight away.

The current study offers at least two theoretical contributions to our thinking about online impression management. First, the results of this study, together with previous research (e.g., Toma \& Hancock, 2010), suggest that research on online dating and other forms of online impression management can benefit from combining the two-component model of impression management (Leary \& Kowalski, 1990) and the hyperpersonal model of CMC (Walther, 1996). The current study is one of the first to show that this combination of frameworks can also be applied to investigate self-esteem during online impression management. Second, the study extends theorizing about online impression management and self-esteem by showing that the impression one expects to make on others through an online profile is related to self-esteem already before anyone has seen the profile. When we investigate the effects of online self-presentation on self-esteem we thus should not only keep in mind the actual reactions received in response to an online profile from an actual audience but also take into account expected reactions from the people that one expects will see the profile.

The theoretical framework described could also be applied to other platforms for online self-presentation and to other populations. For example, similar processes and effects may or may not occur among adolescents constructing social network site profiles, professionals in search of a job on a professional online network, and many other situations. The current study may thus offer both new ideas and a theoretical framework for research about the influences on, effects of, and processes underlying impression management in FtF, CMC, and mixed-mode interactions. 


\subsection{Limitations and suggestions for further research}

The relation between expected impressions and self-esteem in the current study should be interpreted with caution as it only shows a relation between the two measured concepts. Theoretically and statistically, the direction of the effect explicated in the current interpretation of the findings is most likely. That said, other explanations need to be ruled out rigorously in future research. More experimental research is needed to test if manipulating the impression one expects to make indeed causes changes in selfesteem. Furthermore, while our measures showed adequate face validity and internal consistency, a further exploration of the psychometric properties of our measures, in particular of the scale we have constructed for expected impression made through profile, may be desirable. Notably, confirmatory factor analysis would provide detailed information about the construct validity of our measures but requires, for meaningful analyses, a larger sample than was available in the current study (Wolf, Harrington, Clark, \& Miller, 2013).

The current study only examines the effects of one factor, namely anticipated mode of subsequent interaction, on expected impressions made through the profile and self-esteem. Examining which other factors impact the expectation that one's profile will make a desired impression on others, and, in this way, self-esteem is an interesting venue for further research. Such research will improve our understanding of what online daters can do to improve or protect their self-esteem during online dating. Furthermore, this study was conducted in the context of heterosexual women constructing online dating profiles. If the findings also apply to other populations and contexts remains to be tested.

The current study specifically investigates influences on romantic self-esteem during the period in which online daters are waiting for responses to their dating profile. However, to formulate more comprehensive recommendations we also need to increase our understanding of the determinants of romantic self-esteem during other periods of online dating. For example, we do not know how (anticipations of) mode switching impact self-esteem during later phases of online dating. Although the anticipation of engaging in CMC has positive effects on romantic self-esteem straight after profile construction, it is possible that a drop in self-esteem occurs when the individual eventually does decide to meet a partner FtF. After an extended period of CMC, in which the interaction partners have formed idealized impressions of each other (Ramirez et al., 2015), meeting FtF may be even more daunting than had the interaction partners met FtF straight away. On the other hand, an extended period of CMC may offer online daters a chance to feel more confident about how they are seen by their partner, making a FtF date less of a threat to self-esteem. More research is needed to identify what choices online daters can make in order to experience high self-esteem during all phases of online dating, from the construction of an online profile to the eventual FtF date.

The current findings are in line with the hyperpersonal model and indicate that CMC, or even the anticipation of CMC, facilitates impression management. However, the experiment presented the anticipation of either computer-mediated chat or FtF interaction as gestalt channels to the participants. As a consequence, we do not know which specific affordances of CMC heightened the expectation of making a desirable impression through the profile. Was it the asynchronicity of CMC that offered a feeling of control over future message construction? Or was it the continued ability to mask certain qualities and maximize others? Investigating the impact of imagined and actual socio-technological affordances of the different modes on online impression management is an interesting venue for further research.
Future research should also investigate the processes underlying the effects of anticipated mode of future interaction on expected impressions made through the profile and, in turn, selfesteem. Based on theory and previous research, we predicted that online daters who anticipated CMC would expect their profile to make a more desirable impression because they would engage in more positive impression construction. However, the current study does not show if, and to what extent, the effects of anticipated mode on self-esteem are due to idealized impression construction, the expectation of idealized impression formation, and/or other mediating mechanisms.

The current study focuses exclusively on the experiences and expectations of individuals constructing impressions through an online profile. As a result, this experiment does not tell us much about the impressions and expectations that potential viewers form based on the profiles. For example, we do not know if viewers of the online profiles indeed form a more desirable impression of individuals who expect to make a more positive impression. Whether or not potential partners also form desirable impressions of each other has important implications for the relationships between individuals who get to know each other online. Previous research has generally focused either on the factors that influence the success of relationships that are established online (e.g., Ramirez et al., 2015; Sheeks \& Birchmeier, 2007) or on factors that impact self-esteem during online communication (e.g., Gross, 2009; Valkenburg et al., 2006). However, to know how one can make online dating both pleasurable and successful we need to understand how online daters can help themselves feel good about potential partners as well as about themselves.

\section{Conclusion}

The current study is one of the first to investigate factors that impact the self-esteem of individuals who have constructed an online profile and have not yet received responses to this profile. Our findings indicate that expectations play an important role in determining self-esteem during this period. Online daters' expectation that they will make a desirable impression on potential dates through their online dating profile was strongly related to their romantic self-esteem. Furthermore, expectations about the mode in which a subsequent interaction would take place strongly influenced the expectation of making a desirable impression and, as a result, romantic self-esteem.

\section{Acknowledgements}

The research described in this manuscript was completed at and funded by the Amsterdam School of Communication Research, University of Amsterdam.The author would like to thank Jochen Peter, Patti Valkenburg, and Joe Walther for their valuable feedback during the set-up of the study and the preparation of this manuscript.

\section{References}

boyd, D. (2010). Social network sites as networked publics: affordances, dynamics, and implications. In Z. Papacharissi (Ed.), A networked self: Identity, community and culture on social network sites (pp. 39-58). New York, NY: Routledge.

Baumeister, R. F. (1982). A self-presentational view of social phenomena. Psychological Bulletin, 91, 3-26. http://dx.doi.org/10.1037/0033-2909.91.1.3.

Blackhart, G. C., Fitzpatrick, J., \& Williamson, J. (2014). Dispositional factors predicting use of online dating sites and behaviors related to online dating Computers in Human Behavior, 33, 113-118. http://dx.doi.org/10.1016/ j.chb.2014.01.022.

Cohen, J. (1992). A power primer. Psychological Bulletin, 112, 155-159. http:/ dx.doi.org/10.1037/0033-2909.112.1.155.

DeAndrea, D. C., \& Walther, J. B. (2011). Attributions for inconsistencies between online and offline self-presentations. Communication Research, 38, 805-825. 
http://dx.doi.org/10.1177/0093650210385340.

Ellison, N. B., Hancock, J. T., \& Toma, C. L. (2012). Profile as promise: a framework for conceptualizing veracity in online dating self-presentations. New Media \& Society, 14, 45-62. http://dx.doi.org/10.1177/1461444811410395.

Ellison, N., Heino, R., \& Gibbs, J. (2006). Managing impressions online: selfpresentation processes in the online dating environment. Journal of Computer-Mediated Communication, 11, 415-441. http://dx.doi.org/10.1111/ j.1083-6101.2006.00020.x.

Finkel, E. I., Eastwick, P. W., Karney, B. R., Reis, H. T., \& Sprecher, S. (2012). Online dating: a critical analysis from the perspective of psychological science. Psychological Science in the Public Interest, 13, 3-66. http://dx.doi.org/10.1177/ 1529100612436522

Gibbs, J. L., Ellison, N. B., \& Heino, R. D. (2006). Self-presentation in online personals: the role of anticipated future interaction, self-disclosure, and perceived success in internet dating. Communication Research, 33, 152-177. http://dx.doi.org/ $10.1177 / 0093650205285368$.

Gross, E. F. (2009). Logging on, bouncing back: an experimental investigation of online communication following social exclusion. Developmental Psychology, 45, 1787-1793. http://dx.doi.org/10.1037/a0016541.

Hall, J. A., Park, N., Song, H., \& Cody, M. J. (2010). Strategic misrepresentation in online dating: the effects of gender, self-monitoring, and personality traits. Journal of Social and Personal Relationships, 27, 117-135. http://dx.doi.org/10.117/ 0265407509349633.

Harter, S. (1988). Manual for the self-perception profile for adolescents. Denver, CO: Department of Psychology, University of Denver.

Hayes, A. F.. (2012). PROCESS [Macro]. Retrieved from http://afhayes.com/ introduction-to-mediation-moderation-and-conditional-process-analysis.html.

Jin, S. V., \& Martin, C. (2015). “A match made... online?" the effects of usergenerated online dater profile types (free-spirited versus uptight) on other users' perception of trustworthiness, interpersonal attraction, and personality. Cyberpsychology, Behavior, and Social Networking, 18, 320-327. http:/| dx.doi.org/10.1089/cyber.2014.0564.

Lawson, H. M., \& Leck, K. (2006). Dynamics of internet dating. Social Science Computer Review, 24, 189-208, http://dx.doi.org/10.1177/0894439305283402.

Leary, M. R., \& Kowalski, R. M. (1990). Impression management: a literature review and two-component model. Psychological Bulletin, 107, 34-47. http://dx.doi.org/ 10.1037/0033-2909.1071.34.

Litt, E. (2012). Knock, knock. Who's there? the imagined audience. Journal of Broadcasting \& Electronic Media, 56, 330-345. http://dx.doi.org/10.1080/ 08838151.2012.705195.

McLaughlin, C., Vitak, J., \& Crouse, J. (2011). Online identity construction and expectation of future interaction. In Proceedings of the 44th hawaii international conference on system sciences, USA (pp. 1-10). http://dx.doi.org/10.1109/ HICSS.2011.329.

Ramirez, A., (Bryant) Sumner, E. M., Fleuriet, C., \& Cole, M. (2015). When online dating partners meet offline: the effect of modality switching on relational communication between online daters. Journal of Computer-Mediated Communication, 20, 99-114. http://dx.doi.org/10.1111/jcc4.12101.

Schlenker, B. R., \& Leary, M. R. (1982). Social anxiety and self-presentation: a conceptualization model. Psychological Bulletin, 92, 641-669. http://dx.doi.org/ 10.1037/0033-2909.92.3.641.

Schouten, A. P., Valkenburg, P. M., \& Peter, J. (2007). Precursors and underlying processes of adolescents' online self-disclosure: developing and testing an "Internet-attribute-perception“ model. Media Psychology, 10, 292-315. http:/ dx.doi.org/10.1080/15213260701375686.

Shaw, L. H., \& Gant, L. M. (2002). In defense of the Internet: the relationship between internet communication and depression, loneliness, self-esteem, and perceived social support. Cyberpsychology \& Behavior, 5, 157-171. http:// dx.doi.org/10.1089/109493102753770552.

Sheeks, M. S., \& Birchmeier, Z. P. (2007). Shyness, sociability, and the use of computer-mediated communication in relationship development. Cyberpsychology \& Behavior, 10, 64-70. http://dx.doi.org/10.1111/j.10836101.2006.00030.x.

Sprecher, S. (2014). Initial interactions online-text, online-audio, online-video, or face-to-face: effects of modality on liking, closeness, and other interpersonal outcomes. Computers in Human Behavior, 31, 190-197. http://dx.doi.org/10.1016/ j.chb.2013.10.029.

Swann, W. B., Chang-Schneider, C., \& Larsen McClarty, K. (2007). Do people's selfviews matter? Self-concept and self-esteem in everyday life. American Psychologist, 62, 84-94. http://dx.doi.org/10.1037/0003-066X.62.2.84.

Toma, C. L., \& Carlson, C. L. (2015). How do Facebook users believe they come across in their profiles? A meta-perception approach to investigating Facebook selfpresentation. Communication Research Reports, 32, 93-101. http://dx.doi.org/ 10.1080/08824096.2014.990557.

Toma, C. L., \& Hancock, J. T. (2010). Looks and lies: the role of physical attractiveness in online dating self-presentation and deception. Communication Research, 37, 335-351. http://dx.doi.org/10.1177/0093650209356437.

Valkenburg, P. M., Peter, J., \& Schouten, A. P. (2006). Friend networking sites and their relationship to adolescents' well-being and social self-esteem. Cyberpsychology \& Behavior, 9, 584-590. http://dx.doi.org/10.1089/cpb.2006.9.584.

Walther, J. B. (1996). Computer-mediated communication: impersonal, interpersonal, and hyperpersonal interaction. Communication Research, 23, 3-43. http:/ dx.doi.org/10.1177/009365096023001001.

Walther, J. B. (2007). Selective self-presentation in computer-mediated communication: hyperpersonal dimensions of technology, language, and cognition. Computers in Human Behavior, 23, 2538-2557. http://dx.doi.org/10.1016/ j.chb.2006.05.002.

Walther, J. B., \& Tong, S. T. (2014). Inventing partners in computer-mediated communication: how CMC sustains self-fulfilling prophecies and relational attributions. In G. Meiselwitz (Ed.), Social computing and social media (pp. 517-527). Switzerland: Springer International Publishing.

Wolf, E. J., Harrington, K. M., Clark, S. L., \& Miller, M. W. (2013). Sample size requirements for structural equation models an evaluation of power, bias, and solution propriety. Educational and Psychological Measurement, 73, 913-934. http://dx.doi.org/10.1177/0013164413495237.

Yang, C. C., \& Brown, B. B. (2016). Online self-presentation on facebook and self development during the college transition. Journal of Youth and Adolescence, 45 , 402-416. http://dx.doi.org/10.1007/s10964-015-0385-y. 